Dinamika Sosial Budaya, Vol 22, No. 1, Juni 2020, pp 21-28

p-ISSN: 1410-9859\& e-ISSN: 2580-8524

http://journals.usm.ac.id/index.php/jdsb

\title{
STIGMA TERHADAP PEMUDA DENGAN STATUS LAJANG (STUDI KUALITATIF)
}

Dwi Hardani Oktawirawan

Fakultas Psikologi, Universitas Surabaya

dhoktawirawan@gmail.com

\begin{abstract}
Abstrak
Seseorang dengan status lajang tidak terlepas dari adanya stigma negatif seperti dianggap kesepian dan gagal menjalin hubungan romantis. Penelitian ini bertujuan untuk memahami stigma yang dialami oleh lajang dan dampaknya. Selain itu juga digali mengenai kondisi nyata dari seseorang yang berstatus lajang. Metode kualitatif digunakan dengan melakukan wawancara mendalam terhadap subyek yang merupakan seorang lajang yang menerima stigma negatif. Hasil penelitian ini menunjukkan bahwa subyek sering mendapatkan pertanyaan mengenai status lajangnya, dibandingbandingkan dengan orang lain, dan dianggap tidak laku. Kondisi tersebut membuat subyek merasa terganggu dan tidak nyaman hingga akhirnya subyek menjadi sering menghindari orang-orang yang memberikan stigma. Pada kenyataannya subyek tidak merasa kesepian karena menurutnya kebahagiaan tidak hanya diukur dari kondisi relasi romantis.
\end{abstract}

\begin{abstract}
Someone with single status is inseparable from negative stigma, such as being considered lonely and failing to have a romantic relationship. This study aims to understand the stigma experienced by singles and their impact. It also explored the real conditions of someone who is single. The qualitative method is used by conducting in-depth interviews with subjects who are single people who receive a negative stigma. The results of this study indicate that subjects often get questions about their single status, compared with others, and are considered unsold. These conditions make the subject feel disturbed and uncomfortable until finally the subject becomes often avoiding people who provide stigma. In fact the subject does not feel lonely because according to him happiness is not only measured by the conditions of romantic relations.
\end{abstract}

Keywords: Humiliation; Romantic Relation; Single; Stigma 
Dinamika Sosial Budaya, Vol 22, No. 1, Juni 2020, pp 21-28

p-ISSN: 1410-9859\& e-ISSN: 2580-8524

http://journals.usm.ac.id/index.php/jdsb

\section{PENDAhULUAN}

Seseorang yang tidak memiliki pasangan biasanya disebut dengan istilah lajang atau single. Selain itu juga terdapat istilah jomblo yang cukup sering digunakan oleh masyarakat Indonesia (Cindy, 2016). Meskipun bukan kata baku istilah jomblo seringkali dijumpai baik dalam percakapan langsung maupun di dunia maya. Istilah ini berasal dari kata jomlo yang berarti gadis tua yang selanjutnya berubah makna menjadi jomblo yang artinya seseorang yang tidak memiliki pasangan (Cindy, 2016; Noverino, 2015). Dibandingkan dengan kata lajang, istilah jomblo biasanya dianggap lebih santai untuk digunakan dalam kehidupan sehari-hari.

Seseorang yang berstatus jomblo atau lajang terbagi menjadi dua macam, yaitu lajang yang dikarenakan kondisi yang memang membuatnya tidak memiliki pasangan dan lajang yang memang atas kehendak atau pilihannya sendiri untuk tidak menjalin hubungan romantis dengan orang lain (Slonim, Gur-Yaish, \& Katz, 2015). Status lajang ini sering diasosiasikan dengan kondisi yang menyedihkan karena orang yang menyandang status lajang tidak memiliki pasangan (Cindy, 2016; Depaulo \& Morris, 2006; Sudarsono, 2017). Seseorang yang lajang karena kondisi yang membuatnya sendiri biasanya dianggap gagal menjalin hubungan dengan orang lain, kurang menarik, dan pantas dikasihani. Sedangkan seseorang yang memang memutuskan untuk lajang dianggap menutup diri atau hanya peduli dengan kepentingannya sendiri (Depaulo \& Morris, 2006; Greitemeyer, 2009).

Seorang lajang juga tidak jarang dianggap berpenampilan jelek atau tidak menarik bagi orang lain (Depaulo \& Morris, 2006; Greitemeyer, 2009). Kondisi tersebut kemudian dikaitkan dengan perasaan kesepian, tidak bahagia, kurang percaya diri, tidak pandai mencari pasangan, dan tidak mampu bersosialisasi dengan baik (Depaulo \& Morris, 2006; Greitemeyer, 2009; Himawan, Bambling, \& Edirippulige, 2018; Septiana \& Syafiq, 2013; Sudarsono, 2017). Pada beberapa kasus status lajang terkadang juga dikaitkan dengan tuduhan homoseksual karena tidak memiliki pasangan yang merupakan lawan jenisnya (Himawan et al., 2018). Stigma negatif yang melekat pada status lajang akhirnya dijadikan bahan untuk membuat penghinaan, ejekan, sindiran, dan lelucon untuk merendahkan siapapun yang tidak memiliki pasangan (Sudarsono, 2017).

Status lajang dan khususnya istilah jomblo seolah menjadi populer di berbagai bahasan untuk mengangkat stigma negatif yang melekat pada seorang lajang (Putri, 2018). Penghinaan dan lelucon mengenai kondisi seorang lajang yang dianggap menyedihkan bagaikan hal yang wajar di media sosial (Sudarsono, 2017). Selain itu penghinaan tidak langsung juga terjadi dalam obrolan mengenai relasi romantis. Orang terdekat seringkali mencoba menawarkan diri untuk membantu mencarikan pasangan meskipun tidak diminta (Septiana \& Syafiq, 2013). Secara tidak langsung orang tersebut menganggap bahwa teman atau kerabatnya yang lajang tidak mampu mencari pasangan sendiri.

Media sosial juga memiliki kontribusi dalam maraknya penyebaran konten-konten lelucon yang menyudutkan lajang baik dalam bentuk video, gambar meme, bahkan kutipankutipan yang diucapkan oleh public figure. Meskipun demikian tidak banyak orang yang menyadari bahwa stigma negatif terhadap lajang dapat berdampak negatif bagi orang yang menerima stigma tersebut (Depaulo \& Morris, 2006). Penghinaan terhadap lajang dapat berdampak pada munculnya perasaan tidak nyaman ketika seseorang menerima ejekan terkait statusnya sebagai lajang (Septiana \& Syafiq, 2013). Pada kondisi selanjutnya stigma tersebut dapat menimbulkan ketakutan pada seseorang untuk menjadi lajang dan berdampak pada terjalinnya hubungan 
romantis yang yang tergesa-gesa dan lebih berorientasi pada status semata dibandingkan kualitas hubungan (Spielmann et al., 2013).

Realita yang ada mengenai stigma terhadap lajang membuat penelitian ini menarik untuk dilakukan. Pengalaman yang dirasakan oleh seorang lajang terkait stigma masyarakat bisa digali secara mendalam beserta respon yang dialami atau dilakukan oleh subyek. Kondisi nyata dari subyek juga digali untuk dapat membandingkan antara stigma yang dipercayai masyarakat dengan kondisi lajang sesungguhnya. Diharapkan penelitian ini dapat menjadi salah satu dorongan agar kita lebih sadar akan stigma yang biasa diberikan kepada lajang dan apa dampaknya. Sehingga ke depannya bisa terjadi penurunan tingkat stigma dan penghinaan yang terjadi pada masyarakat terhadap orang-orang yang memiliki status lajang.

\section{METODE}

Penelitian ini menggunakan metode kualitatif dengan model analisis wacana kritis. Fokus dalam penelitian ini adalah menggali stigma-stigma yang dirasakan atau diterima oleh seseorang yang memiliki status lajang. Selain itu peneliti ini juga menggali kondisi sesungguhnya yang dialami oleh subyek sehingga dapat dibandingkan antara stigma yang ada dengan kondisi riil subyek. Subyek dalam penelitan ini merupakan seseorang yang memiliki status sebagai lajang atau tidak sedang memiliki pasangan. Hal ini bertujuan agar subyek mampu menyampaikan pengalamannya mengenai stigma terhadap lajang secara akurat karena memang masih dirasakan oleh subyek hingga saat proses pengambilan data atau wawancara berlangsung. Syarat lainnya yaitu pernah mendapatkan stigma atau penghinaan dari orang lain terkait dengan statusnya sebagai lajang.

Teknik pengumpulan data dalam penelitian ini menggunakan wawancara semiterstruktur. Wawancara tatap muka dilakukan pada bulan Oktober 2019 bertempat di Kota Surabaya. Pemilihan waktu dan tempat dilakukan berdasarkan persetujuan antara peneliti dengan subyek penelitian. Selama proses wawancara peneliti melakukan pengambilan suara menggunakan sound recorder yang terdapat di telepon genggam peneliti dengan persetujuan subyek. Hal ini dilakukan untuk mempermudah proses pembuatan transkrip wawancara dan untuk menghindari adanya kesalahan penulisan atau tidak lengkapnya data yang dilaporkan.

Teknik analisis data yang digunakan dalam penelitian ini adalah analisis wacana kritis. Dalam analisis wacana kritis dilakukan identifikasi wacana yaitu ide-ide atau asumsiasumsi yang ada dibalik fenomena yang sedang diteliti. Kemudian menganalisa subyektivitas yang dimungkinkan oleh wacana-wacana yang ada pada fenomena tersebut. Selanjutnya digali tindakan atau konsekuensi yang mungkin terjadi atau mungkin dibatasi terkait dengan subyektivitas wacana yang ada. Setelah itu menentukan wacana alternatif atau resistensi yang mungkin dapat menggoyahkan wacana yang dominan dimana dalam penelitian ini adalah kondisi nyata dari subyek yang tidak sesuai dengan stigma yang ada.

\section{HASIL DAN PEMBAHASAN}

\subsection{Gambaran Subyek}

Subyek merupakan seorang pegawai di salah satu perusahaan swasta di Kota Surabaya. Saat ini subyek tinggal di salah satu rumah kos di Kota Surabaya tidak jauh dari lokasi dia bekerja. Saat ini subyek tidak memiliki seorang pasangan atau berstatus lajang. Sebelumnya subyek pernah berpacaran beberapa kali hingga terkahir subyek memiliki pasangan adalah pada tahun 2015. Selama beberapa tahun terakhir subyek memutuskan untuk tetap lajang karena memang pilihannya sendiri. Meskipun subyek memiliki harapan untuk mendapatkan pasangan, namun subyek merasa belum menemukan seseorang yang cocok dengan 
Dinamika Sosial Budaya, Vol 22, No. 1, Juni 2020, pp 21-28

p-ISSN: 1410-9859\& e-ISSN: 2580-8524

http://journals.usm.ac.id/index.php/jdsb

kriterianya. Selain itu subyek juga mengaku masih berfokus dengan prioritasnya pribadi seperti mengejar karir dan cita-citanya. Sehingga status lajang menurut subyek bukanlah kemalangan melainkan memang telah menjadi pilihan yang diambil oleh subyek.

\subsection{Pemaknaan Istilah Jomblo}

Subyek beranggapan bahwa kebanyakan orang mengartikan jomblo berbeda dengan single. Seorang dengan status jomblo dianggap tidak memiliki pasangan karena takdir sedangkan seorang single tidak memiliki pasangan karena keputusan atau pilihannya sendiri. "Cuman orang-orang pada umumnya itu mendefinisikan menjadi dua hal yang berbeda bahwa jomblo itu memang udah takdirnya dia tidak ada pasangan, tapi kalau single itu pilihan," ungkap subyek ketika menceritakan pandangan masyarakat terkait istilah jomblo (Data Wawancara). Perbedaan makna ini biasanya disebut sebagai voluntary single dan involuntary single (Slonim et al., 2015). Voluntary single adalah orang yang memilih untuk sendiri sedangkan involuntary single adalah orang yang terpaksa sendiri karena sebenarnya menginginkan adanya seorang pasangan.

Dengan adanya perbedaan pemaknaan antara istilah jomblo dan single mengakibatkan adanya persepsi bahwa seseorang dengan status jomblo lebih rendah dari pada seorang yang mengaku single. "Karena kan mereka, maksudnya kalau dikatain jomblo mereka akan merasa kayak direndahkan, sedangkan mereka yang dikatakan single merasa ah dirinya bagus, dirinya lebih tinggi daripada jomblo," ucap subyek menjelaskan hal tersebut (Data Wawancara). Jomblo seringkali memang dianggap menyedihkan karena kondisinya dianggap memprihatinkan (Cindy, 2016; Sudarsono, 2017).

Menurut subyek jomblo memiliki makna yang sama dengan istilah lain seperti single. Kedua istilah tersebut merujuk pada kondisi seseorang yang sedang tidak memiliki pasangan. "Karena secara makna juga jomblo itu kan sendiri yang dia nggak berpasangan, single juga nggak berpasangan. Cuman bedanya jomblo bahasa Indonesia, single bahasa Inggris," jelas subyek mengenai makna jomblo (Data Wawancara). Dalam penggunaan umum di Indonesia, kata jomblo memang merujuk pada seseorang yang tidak memiliki pasangan baik itu yang belum pernah sama sekali atau yang baru saja putus dari hubungan sebelumnya (Cindy, 2016; Noverino, 2015).

\subsection{Stigma yang Dialami}

Berdasarkan hasil wawancara yang telah dilakukan, terdapat beberapa perilaku yang diterima dari orang lain terkait stigma terhadap status jomblo atau lajang yang dimiliki subyek. Ketika bertemu dengan orang lain subyek seringkali mendapatkan pertanyaan mengenai status jomblo yang dimilikinya. Subyek selalu diberi pertanyaan mengenai alasan mengapa dirinya tidak segera memiliki pasangan. "Lebih ke bertanya, tapi merujuk ke mengejek mengolok. Lebih ke, dan lebih konfirmasi kenapa sih harus jadi, eh harus sendiri, kenapa nggak mau cari. Lebih ke kepo sih, kepo," ungkap subyek (Data Wawancara). Dalam prakteknya pertanyaan terkait status pernikahan memang menjadi hal yang wajar untuk diutarakan di Indonesia (Himawan et al., 2018). Pertanyaan tersebut muncul karena seseorang yang mendapatkan stigma yaitu lajang dianggap tidak sesuai dengan nilai-nilai yang ada pada orang lain (Major \& O'Brien, 2005).

Pertanyaan tentang status lajang yang dimiliki subyek datang dari keluarga besar yang biasanya bertemu di momen-momen tertentu seperti hari raya agama serta dari teman atau orang lain yang tidak begitu kenal dekat dengan subyek. Teman dekat dan keluarga dekat subyek justru tidak pernah mempermasalahkan hal tersebut. 
Dinamika Sosial Budaya, Vol 22, No. 1, Juni 2020, pp 21-28

p-ISSN: 1410-9859\& e-ISSN: 2580-8524

http://journals.usm.ac.id/index.php/jdsb

"Kontennya itu sih lebih ke, kalau di keluarga ya, keluarga besar itu lebih tepatnya setiap tahun kan selalu ada kumpul keluarga, hari, hari raya apa, agama. Nah tapi, setiap disitu kan pasti mereka ada yang bawa pacarnya, ada yang bawa istrinya, suaminya atau tunangannya, intinya bawa pasangan.

Dan disatu sisi kan ya aku kesana nggak bawa pasangan kan. Jadi e apa ya, pertanyaan-pertanyaan yang memang agak menggelitik, contoh kayak, udah berapa lama datang kesini kok mesti sendiri, nggak mau bawa pasangan ta? Atau mungkin ada yang langsung nanya, kamu mau nunggu apa kok nggak nikahnikah? Atau ada yang pernah, lebaran atau hari raya tahun depan udah bawa belum? Jadi hal-hal yang menurutku nggak penting sih harus dijawab dan nggak penting ditanyain juga." (Data Wawancara)

Subyek juga seringkali mendapatkan teguran mengenai status lajangnya. Orang lain biasanya menyudutkan subyek seolah-olah tidak memiliki pasangan adalah sesuatu hal yang salah. Dalam hal ini orang lain biasanya juga memberikan nasehat kepada subyek untuk segera mencari pasangan bahkan untuk segera menikah. Subyek juga pernah mendapatkan nasehat untuk segera menikah dari orang yang bahkan tidak dikenalinya yaitu driver ojek online. "Bahkan ada yang nanya usia, waktu nyebutin usia dia bilang, oh harusnya udah nikah, jangan lama-lama mas, udah cari aja, nikah, masalah nanti kerjaannya udah settle apa belum, nggak papa nikah dulu," jelas subyek menceritakan percakapannya dengan seorang driver ojek online (Data Wawancara). Tidak jarang seseorang memberikan dorongan untuk orang lain agar segera berpasangan bahkan ikut campur untuk turut membantu dalam mencarikan pasangan (Septiana \& Syafiq, 2013).
Dalam pertemuan keluarga besar, subyek sering dibanding-bandingkan dengan saudara subyek lainnya yang telah memiliki pasangan. Keluarga subyek menanyakan mengenai perasaan subyek melihat sepupu-sepupunya yang sudah memiliki pasangan dan bahkan menikah. Menurut mereka, sudah selayaknya subyek merasa iri dengan saudara-saudaranya yang memiliki pasangan karena subyek selama ini tidak kunjung memiliki pasangan dan membawa pasangannya ke acara keluarga. "Konten-konten yang biasanya mereka sebutin itu lebih ke, kamu nggak iri ta apa namanya nggak iri melihat saudara-saudara sepupumu e saudaramu yang lain udah punya pasangan masing-masing?" ucap subyek menggambarkan perkataan dari keluarga besarnya (Data Wawancara). Seseorang yang tidak memiliki pasangan biasanya memang dianggap kesepian dan memiliki kondisi yang menyedihkan dibanding dengan yang berpasangan (Sudarsono, 2017).

Subyek juga pernah mendapatkan ejekan terkait statusnya yang tidak memiliki pasangan. Subyek mendapatkan ejekan dari temannya dimana dia dianggap tidak laku akhirnya menjadi jomblo atau lajang. Dalam hal ini konteks pembicaraan yang terjadi adalah bercanda sehingga subyek juga menanggapi teman-temannya dengan candaan juga. "Ehm, kalau (diejek) nggak laku iya pernah. Cuma kalau nggak laku sih konteksnya bercanda. Ya kalau ada waktu omongan kayak gitu pasti jawabnya, ya aku jawab dengan bercanda juga sih," jelas subyek (Data Wawancara). Meskipun demikian subyek terkadang merasa terganggu dengan kata-kata atau pertanyaan yang terlontar dari orang lain mengenai status lajang yang dimilikinya. Seorang lajang biasanya dianggap tidak laku bahkan dianggap jelek, berorientasi dengan diri sendiri, dan kurang mampu bersosialisasi (Depaulo \& Morris, 2006; Septiana \& Syafiq, 2013). Stigma dan prasangka terhadap lajang tersebut terus terjadi karena memang dianggap biasa saja atau 
Dinamika Sosial Budaya, Vol 22, No. 1, Juni 2020, pp 21-28

p-ISSN: 1410-9859\& e-ISSN: 2580-8524

http://journals.usm.ac.id/index.php/jdsb

bisa ditoleransi jika dibandingkan dengan prasangka lainnya (Fisher \& Sakaluk, 2020).

Menghadapi berbagai perilaku terkait stigma yang ada, subyek merasa terganggu karena urusan pribadinya dicampuri oleh orang lain. Subyek merasa tidak nyaman ketika harus menjawab pertanyaan-pertanyaan dari orang lain yang sebenarnya tidak begitu bermanfaat bagi mereka.

"Ehm, mungkin pas, kayaknya nggak pernah deh. Cuman kalau down nggak, tapi merasa tersinggung, iya. Itu mungkin awal-awal ya, awal-awal putus dan setahun nggak ada pasangan itu masih awal-awal, cuman down enggak tapi tersinggung iya. Lebih ke perasaan bahwa kenapa harus ngurus hidup orang lain." (Data Wawancara)

Dalam beberapa situasi akhirnya subyek seringkali memutuskan untuk menghindari obrolan-obrolan yang merujuk pada status lajang yang dimilikinya. "karena setiap ada pertanyaan itu pasti aku tinggal, ke tempat yang lain. Maksudnya meninggalkan individu itu ke yang lainnya," ungkap subyek (Data Wawancara). Pertanyaan dan sindiran mengenai status jomblo biasanya membuat seseorang menjadi merasa terganggu dan tidak nyaman (Septiana \& Syafiq, 2013).

Selain itu subyek juga menceritakan bahwa ada beberapa temannya yang akhirnya menutupi status lajangnya agar tidak mendapatkan ejekan atau perundungan dari orang lain. "Sebenernya ada temenku sih yang dia baru putus sama pacarnya dan intinya ya waktu itu aku tau bahwa dia udah putus, dia nggak mau ngasih tau ke semua, ke sahabatnya ke temen-temennya bahwa dia sudah tidak berpasangan lagi. Karena dia takut nanti dianggap jomblo lagi," jelas subyek (Data Wawancara). Status jomblo memang sering menjadi hal yang ditakuti bahkan ada yang rela mempertahankan hubungan dengan adanya kekerasan daripada dia harus putus dan menyandang status jomblo (Ariestina, 2009; Spielmann et al., 2013).

\subsection{Kondisi Nyata Subyek}

Sebagai seorang lajang subyek merasa bahwa apa yang dikatakan atau dipandang orang-orang mengenai statusnya bukanlah hal yang sepenuhnya benar. Tidak semua orang menjadi lajang karena tidak laku atau tidak kunjung mendapatkan pasangan yang dicari. Subyek sendiri memutuskan untuk tetap sendiri karena masih berfokus dengan tujuan-tujuan pribadinya. "Jadi masih pingin menjalani hidup yang sesuai tujuan aja sih, sesuai tujuan dan ambisi pribadi. Jadi kalaupun ada yang cocok akhirnya terbentur dengan idealisme pribadi dan akhirnya nggak jadi," ungkap subyek (Data Wawancara).

Selain itu subyek juga memang belum menemukan pasangan yang dianggap memiliki prinsip yang sama dan dapat mendukung dirinya. Subyek tidak ingin hadirnya pasangan justru menghambat dia dalam mengejar tujuan pribadi. "Jadi bukan hubungan yang satu produktif satunya kurang produktif dan akhirnya mengganggu yang produktif," jelas subyek (Data Wawancara).

Menjadi seorang lajang adalah hal yang tidak menyedihkan dan bahkan bisa dianggap sebagai hal yang menyenangkan. Subyek merasa bahwa dia lebih fleksibel karena bisa bebas mengatur kehidupannya sendiri. "Tapi malah lebih milih lebih setelah empat tahun jalan sendiri malah merasa apa sendiri itu menyenangkan ya. Kayak being single itu kayaknya fine fine aja," ucap subyek (Data Wawancara). Dengan tidak adanya pasangan, subyek merasa tidak perlu memberi kabar setiap hari kepada pasangan sehingga lebih bebas dan dapat fokus dengan tujuan atau prioritas pribadinya. Menurut subyek menjadi sendiri bukan berarti selalu merasa sendiri. Tidak adanya seorang pasangan bukanlah menjadi masalah besar yang membuat seorang 
lajang kesepian. "Se, sendiri dan merasa sendiri itu beda sih menurutku. Kalau aku pribadi sih nggak, emang pengen sendiri, tapi kalau misalnya kesepian nggak kayaknya. Karena ya memang pilihan," jelas subyek (Data Wawancara). Seorang lajang juga biasanya mampu memiliki kehidupan yang bahagia bahkan seringkali dianggap lebih mandiri dan bebas (Girme, Overall, Faingataa, \& Sibley, 2016; Himawan, Bambling, \& Edirippulige, 2017; Septiana \& Syafiq, 2013).

Seorang lajang juga memiliki support system yang berasal dari lingkungan kerja, pertemanan, juga keluarga. Teman-teman dan keluarga subyek mampu memberikan dukungan dalam berbagai hal sehingga subyek tidak merasakan kesepian. "Enggak, sendirian banget sih nggak, kesepian banget enggak. Karena kan dibalik sendiri kan punya aktivitas, punya kegiatan di luar kerjaan, terus ada temen-temen dan ada keluarga, ada sahabat sih, jadi ada support system," ungkap subyek yang menjelaskan bahwa dirinya tidak merasa kesepian (Data Wawancara). Sumber kebahagiaan seseorang memang tidak hanya berasal dari relasi romantis saja, namun juga bisa berasal dari keluarga, saudara, teman, dan sumber lainnya (Depaulo \& Morris, 2006; Greitemeyer, 2009). Pada penelitian yang dilakukan oleh Sarkisian \& Gerstel (2015) juga menunjukkan bahwa orang-orang lajang memiliki hubungan yang lebih intens dengan lingkungannya seperti keluarga, saudara, dan teman dibandingkan dengan orang-orang yang sudah memiliki pasangan.

\section{KESIMPULAN}

Subyek memaknai bahwa jomblo atau single adalah seseorang yang tidak memiliki pasangan. Terkait dengan status hubungannya tersebut subyek tidak jarang mendapatkan berbagai stigma dari orang lain. Dia sering mendapatkan pertanyaan mengenai statusnya, dibanding-bandingkan dengan orang lain, bahkan dianggap tidak laku. Biasanya yang memberikan stigma kepada subyek adalah orang-orang yang tidak terlalu dekat seperti teman, keluarga besar, bahkan orang yang baru saja kenal seperti driver ojek online. Terkait stigma ini subyek merasa terganggu dan tidak nyaman sehingga tidak jarang subyek menghindari orang-orang yang mencoba ikut campur dengan urusan statusnya.

Pada kenyataannya subyek tidak bermasalah dengan statusnya saat ini sebagai seorang lajang. Subyek merasa bahagia bahkan menganggap bahwa hidupnya lebih fleksibel tanpa adanya pasangan. Menjadi seorang lajang bukanlah hal yang menyedihkan terutama karena subyek memang memilih untuk tidak memiliki pasangan untuk sementara waktu. Subyek juga tidak merasakan kesepian karena ada support system yang berasal dari temanteman dekatnya dan keluarganya di rumah. Sehingga menjadi seorang lajang tidak selalu menjadi hal yang memprihatinkan karena kebahagiaan seseorang tidak hanya diukur dari relasi romantis yang dimilikinya.

\section{DAFTAR PUSTAKA}

Ariestina, D. (2009). Kekerasan dalam pacaran pada siswi SMA di Jakarta. Jurnal Kesehatan Masyarakat Indonesia, 3(4), 161-170.

Cindy, N. (2016). Representasi meme jomblo dalam situs jejaring sosial twitter (analisis semiotika Roland Barthes ). Jurnal Online Mahasiswa (JOM) Bidang Ilmu Sosial Dan Ilmu Politik, 3(2), 1-14.

Depaulo, B. M. \& Morris, W. L. (2006). The unrecognized stereotyping and discrimination against singles. Curent Directions in Psychological Science, 155(5), 251-254.

Fisher, A. N. \& Sakaluk, J. K. (2020). Are single people a stigmatized 'group'? Evidence from examinations of social identity, entitativity, and perceived responsibility. Journal of Experimental Social Psychology, 86, 1-15.

Girme, Y. U., Overall, N. C., Faingataa, S., \& Sibley, C. G. (2016). Happily single: The link between relationship status and wellbeing depends on avoidance and approach 
Dinamika Sosial Budaya, Vol 22, No. 1, Juni 2020, pp 21-28

p-ISSN: 1410-9859\& e-ISSN: 2580-8524

http://journals.usm.ac.id/index.php/jdsb

social goals. Social Psychological and Personality Science, 7(2), 122-130.

Greitemeyer, T. (2009). Stereotypes of singles : Are singles what we think? European Journal of Social Psychology, 39(3), 368383.

Himawan, K. K., Bambling, M., \& Edirippulige, S. (2017). Modernization and singlehood in Indonesia: Psychological and social impacts. Kasetsart Journal of Social Sciences, 1-8.

Himawan, K. K., Bambling, M., \& Edirippulige, S. (2018). What does it mean to be single in Indonesia? Religiosity, social stigma, and marital status among never-married Indonesian adults. SAGE Open, 8(3), 1-9.

Major, B. \& O'Brien, L. T. (2005). The social psychology of stigma. Annual Review of Psychology, 56(1), 393-421.

Noverino, R. (2015). Kajian analisis wacana kritis intertekstualitas (interdiskursivitas) pada terjemahan yang menggunakan bahasa gaul. Prosiding PESAT, 6, 108116.

Putri, R. D. D. G. S. (2018). The force to be in a relationship; how actors play their roles on instagram accounts in shaping a negative image of single late millenial in Indonesia.
International Review of Humanities Studies, 3(1), 28-38.

Sarkisian, N. \& Gerstel, N. (2015). Does singlehood isolate or integrate? Examining the link between marital status and ties to kin, friends, and neighbors. Journal of Social and Personal Relationships, 33(3), 361-384.

Septiana, E. \& Syafiq, M. (2013). Identitas "lajang" (single identity) dan stigma: studi fenomenologi perempuan lajang di Surabaya. Jurnal Psikologi Teori \& Terapan, 4(1), 71-86.

Slonim, G., Gur-Yaish, N., \& Katz, R. (2015). By choice or by circumstance?: Stereotypes of and feelings about single people. Studia Psychologica, 57(1), 35-48.

Spielmann, S. S., MacDonald, G., Maxwell, J. A., Joel, S., Peragine, D., Muise, A., \& Impett, E. A. (2013). Settling for less out of fear of being single. Journal of Personality and Social Psychology, 105(6), 1049-1073.

Sudarsono, S. C. (2017). Diskreditisasi dan resistansi jomblo yang terepresentasi dalam wacana meme humor. Prosiding SETALI 2017, 415-419. 